\title{
Numerical Modeling of Stress-Strain State of a Deep Beam
}

\author{
Nikita Mescheulov ${ }^{1, *}$, and Vladimir Barashkov ${ }^{1}$ \\ ${ }^{1}$ Tomsk State University of Architecture and Building, Tomsk 634003 Russia
}

\begin{abstract}
The article presents calculation results for model elastic problem of defining stress-strain state of a deep beam preformed in 3D and 2D statements with the use of ANSYS software package. Geometric relations are taken in the form of Cauchy equations. The purpose of the study is to assess error in the results obtained for the two statements and to draw a conclusion on the possibility of using $2 \mathrm{D}$ statement for the deep beam under study. Based on 3D statement calculation results one may observe a short area near the support surface of a deep beam with the maximum load across the entire thickness. In this area the concentration of maximum stress values and maximum linear and angular deformations in the structure material are observed. The area is located on the axis of symmetry of the deep beam near the inner edge of support surface. It is found that the stress intensity values obtained for the two statements have considerable differences in this area, for that reason 3D statement shall be used when performing calculations for the deep beam. This way of solving the problem is illustrative of stress-strain state parameters distribution across the thickness of the structure, which is necessary for its strength evaluation.
\end{abstract}

\section{Introduction}

In publications on solid mechanics the problem of stress-strain state (SSS) calculation for a deep beam is conventionally solved in $2 \mathrm{D}$ statement [1-3]. In this case stresses $\sigma_{z}, \tau_{z x}, \tau_{z y}$ equal to zero on the sides are neglected inside the beam structure due to smallness of thickness value compared to other parameters. Such state is referred to as plane stress state. The method for solving the problem of finding SSS of a deep beam in 2D statement with the use of finite difference method is widely reported in academic literature [4-9].

Around 1934, while analyzing deep beams scientists P. Pasternak and A. Sinitsyn suggested and implemented an effective technique of finding Airy stress function on the plate boundary by building diagrams for bending moments occurring in the frame having the same configuration as the deep beam form and subjected to the same load. Such technique is called frame analogy method. The implementation of $2 \mathrm{D}$ biharmonic equation of surface elasticity theory is reduced to solving a system of linear algebraic equations for the stress function at the internal nodes of a finite-difference grid. In the cited studies a grid

\footnotetext{
* Corresponding author: nikita.mesheulov@mail.ru
} 
of moderate size is used (the largest is $7 \times 7$ nodes), it is built with the account of geometrical symmetry of the structure itself, its fixing conditions and external load relative to the vertical axis.

Presently, SCAD Office, LIRA, ANSYS and other software packages are used for calculation of deep beams in 2D statement. The finite element method applied in the mentioned software in the form of displacement method is based on variational principle of Lagrange.

The purpose of this study is to estimate the error of the results obtained for $2 \mathrm{D}$ and $3 \mathrm{D}$ statements of a deep beam SSS problem using ANSYS software, as well as to formulate a conclusion on the possibility of using 2D statement for the structure under study.

\section{Method and problem statement}

The study is focused on calculation of elastic SSS of a deep beam (Fig.1) subjected to stepwise uniform external load with the intensity $q$ and $q_{f}$. The weight of the structure, the material of which is considered isotropic, is neglected. Due to two symmetry planes present in the deep beam, external load and support conditions, one quarter of the structure $A B C D 0 F G H$ (Fig. 2) is studied. Symmetry displacement conditions $u$ and $w$ are respectively implemented on the surfaces $0 A B F$ and $0 H G F$.

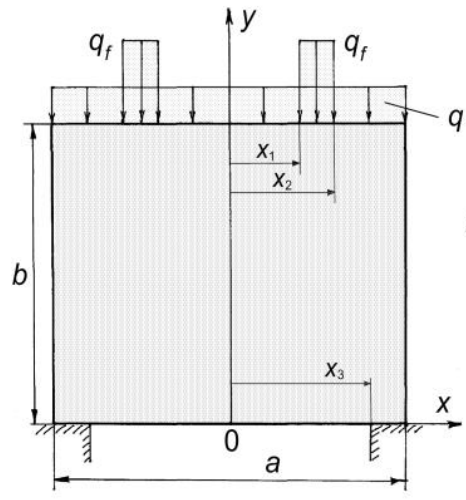

Fig. 1. Deep beam
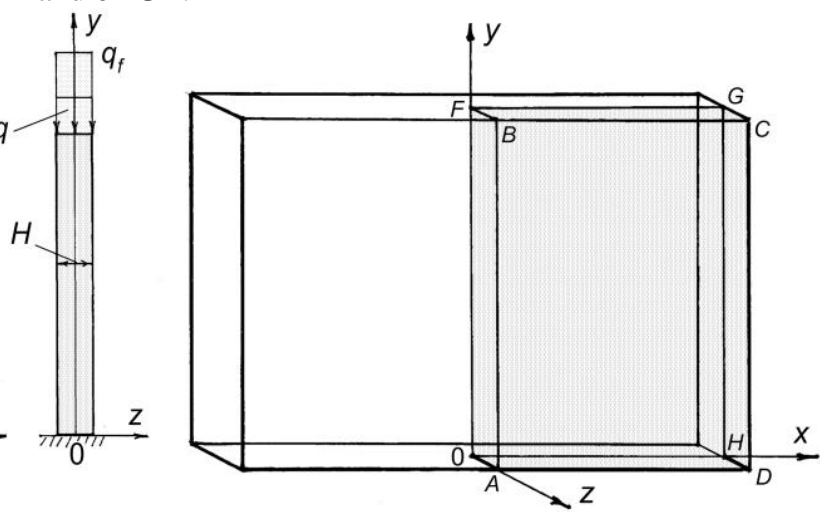

Fig. 2. Calculation area of the deep beam

The following static and geometrical boundary conditions are applied for solving the model problem in 3D statement on the bottom surface of the beam $y=O(O A D H)$ : free surface - $0 \leq x<x_{3}-\sigma_{y}=\tau_{x y}=\tau_{z y}=0$, support surface - $x_{3} \leq x \leq a / 2-u=v=0, \tau_{z y}=0$; on the top surface $y=b(F B C G)$ : surface - $x_{1} \leq x<x_{2}-\sigma_{y}=q+q_{f}, \tau_{x y}=\tau_{z y}=0$, surface $0 \leq x<x_{1}$ и $x_{2} \leq x \leq a / 2-\sigma_{y}=q$, $\tau_{x y}=\tau_{z y}=0$; on the left surface $x=0(0 A B F): u=0, \tau_{y x}=\tau_{z x}=0$; on the free and right surface $x=a / 2(H D C G): \sigma_{x}=\tau_{y x}=\tau_{z x}=0$; on the back surface $z=0(0 H G F): w=0, \tau_{x z}=\tau_{y z}=0$; on the free front side $z=H / 2(A D C B): \sigma_{z}=\tau_{x z}=\tau_{y z}=0$.

Here, $u, v, w$ are projections of the body point displacement vector respectively on the $x, y, z$ axes of the Cartesian coordinate system; $\sigma_{x}, \sigma_{y}, \sigma_{z}, \tau_{x y}, \tau_{y z}, \tau_{z x}$ denote normal stresses and shear stresses.

In this study SSS of a deep beam is determined in 3D and 2D statements with the use ANSYS software package. It shall be noted that the finite element method applied in this software, along with other similar methods based on variational principle of Lagrange, like Ritz method and variational-difference method, provides solutions that automatically satisfy equilibrium equations and surface conditions. When solving a differential problem of the theory of elasticity satisfaction of the mentioned equations may cause significant difficulties. 
Analysis of the deep beam is performed in 3D statement for the following values of geometrical parameters and elastic constants for material and external loads: length $a=8 \mathrm{~m}$, height $b=8 \mathrm{~m}$, thickness $H=0.5 \mathrm{~m}$; Young's modulus $E=2 \times 10^{4} \mathrm{MPa}$, Poison's ratio $v=0.3$; $q=2 \mathrm{MPa}, q_{f}=1.6 \mathrm{MPa} x_{l}=1.75 \mathrm{~m}, x_{2}=2.25 \mathrm{~m}, x_{3}=3.00 \mathrm{~m}$. This structure design is referred to as basic.

For analysis of SSS of a deep beam, the calculated area of which is presented in Figure 2 , the finite element mesh was used with the size of $(128 \times 256 \times 8)$ elements on $(x, y, z)$ axes respectively, as well as $3 \mathrm{D}$ finite elements of $(3.125 \times 3.125 \times 3.125) \mathrm{cm}$.

\section{Results}

\subsection{Results for 3D statement}

Testing of calculation program was performed by solving a problem for the case of supporting a structure with the entire bottom surface under action of load $q$, when linear elastic SSS occurs in the deep beam. In the whole volume of the structure stress $\sigma_{y}=-2$ $\mathrm{MPa}$, whereas the absolute values of all other stresses are four orders of magnitude lower than the stress $\sigma_{y}$. Linear deformations are $\varepsilon_{y}=-0.0001, \varepsilon_{x}=\varepsilon_{z}=0.00003$ and their absolute values are three orders of magnitude higher than that of angular deformations. Displacement along the $y$ axis on the top surface $y=b$ of the deep beam is $v=-0.0008 \mathrm{~m}$. The obtained results are identical to those of analytical solution to strength of materials problem on stresses and strains in a column under axial compression.

Figures 3 and 4 provide illustrations for the basic design of the structure in 3D statement and present stress calculation results for the upper part of the deep beam, where external loads are applied, and for its lower support part. The sufficiently accurate data demonstrate fulfillment of static boundary conditions on the top surface $y=b(F B C G)$ and on the bottom surface free from external loads $y=0(0 A D H)$, where stress is $\sigma_{y}=-2 \mathrm{MPa}$.

In the foreground of all figures given in the article one can see a part of outer edge free of loads $z=H / 2(A D C B)$; on the right is the free surface $x=a / 2(H D C G)$; the symmetry surface $z=0(0 H G F)$ is on the back and is invisible.

The highest stress values in the deep beam are observed in the lower part near the support surface on the $x$ axis for $y=z=0$ (i.e. on the symmetry surface) and their values are equal to $\sigma_{x}=-42.00 \mathrm{MPa}, \sigma_{y}=-38.80 \mathrm{MPa}, \sigma_{z}=-19.20 \mathrm{MPa}, \tau_{x y}=28.83 \mathrm{MPa}$. The values of other shear stresses are one order of magnitude and more lower than the listed ones. The stress value $\sigma_{y}$ corresponds (with the error of less than $1 \%$ ) to the results obtained from the study [10] with the use of variational-difference method. 


\section{EPPS 2019}

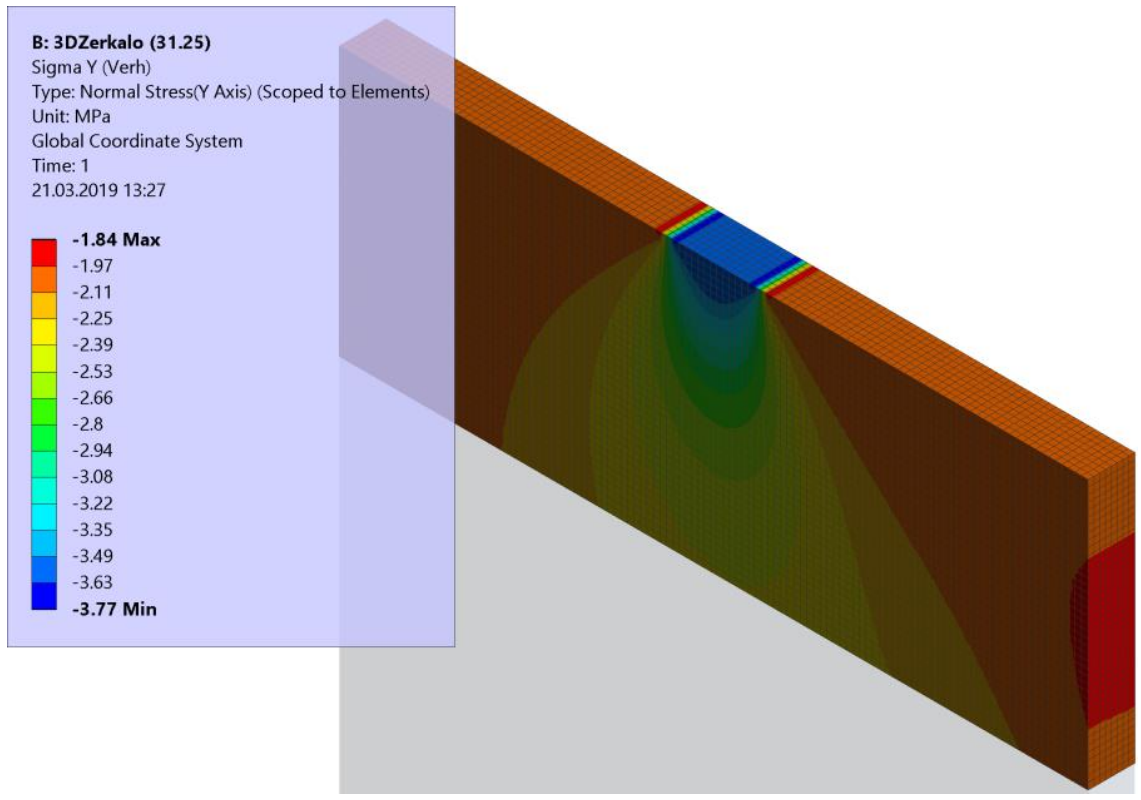

Fig. 3. Distribution of stress $\sigma_{y}$ in the upper part of the deep beam

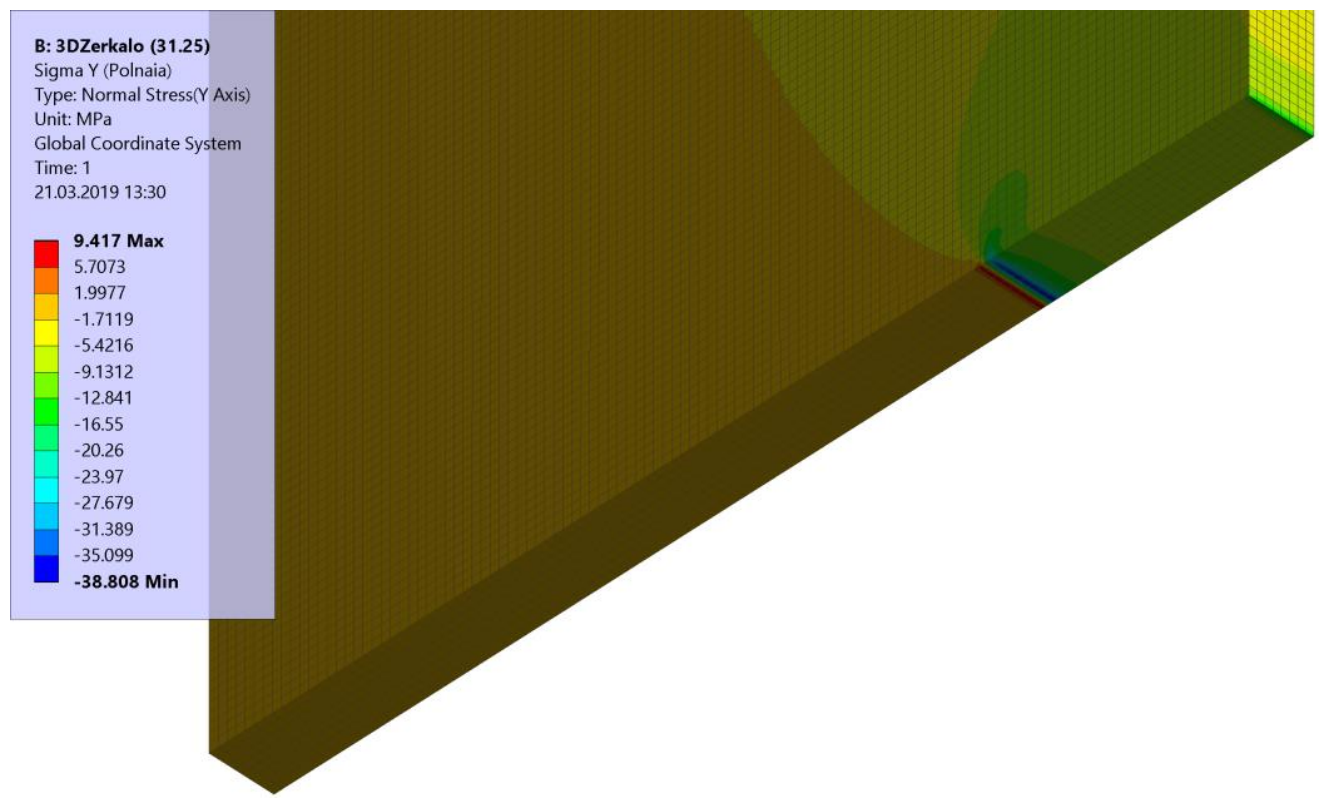

Fig. 4. Distribution of stress $\sigma_{y}$ in the lower part of the deep beam

Linear deformations in the support part of the deep beam near the external surface $z=H / 2$ reach the values of $\varepsilon_{x}=-0.0012, \varepsilon_{y}=-0.0011, \varepsilon_{z}=0.0008$. The highest values of angular deformations are $\gamma_{x z} \approx \pm 0.0004, \gamma_{y z}=-0.0002$. The maximum value $\gamma_{x y}=0.0037$ is higher than that of linear deformations $\gamma_{x z} \approx \pm 0.0004, \gamma_{y z}=-0.0002$, and its negative value is as high as 0.0007 (Fig. 5). 


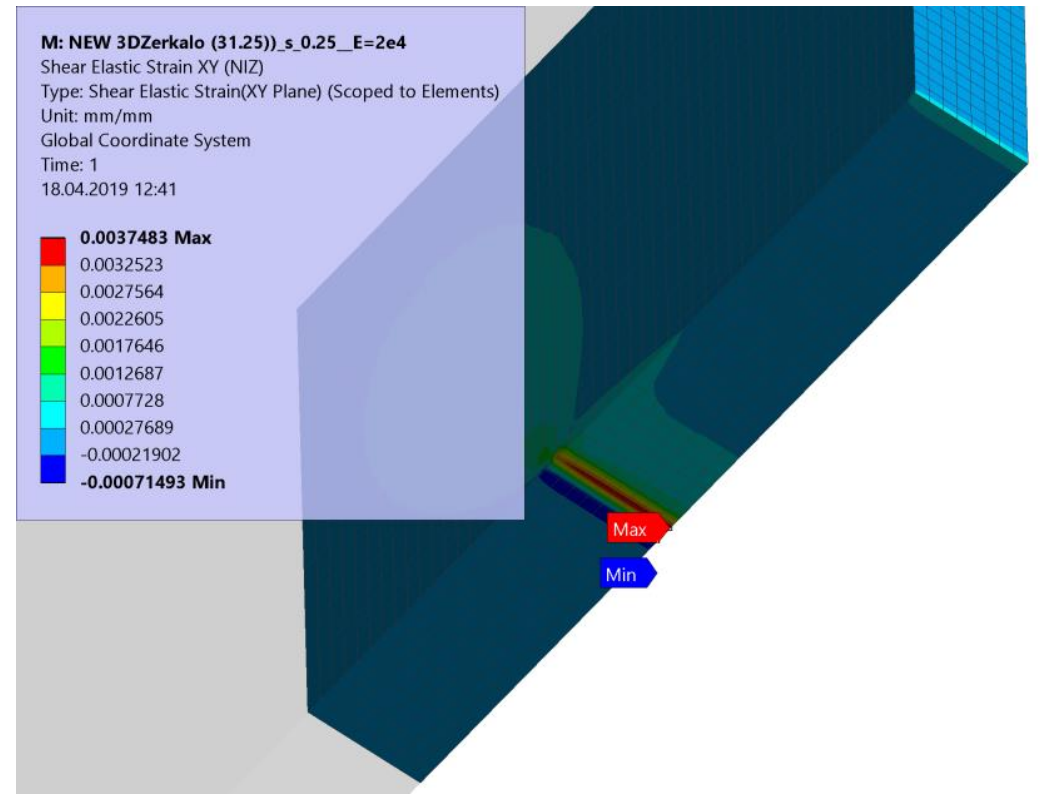

Fig. 5. Distribution of angular deformations $\gamma_{x y}$ in the lower part of the deep beam

Figures 6 and 7 present calculation results for stress intensity $\sigma_{i}$, the notion of which is used in the theory of plasticity and when determining ultimate strength of the material.

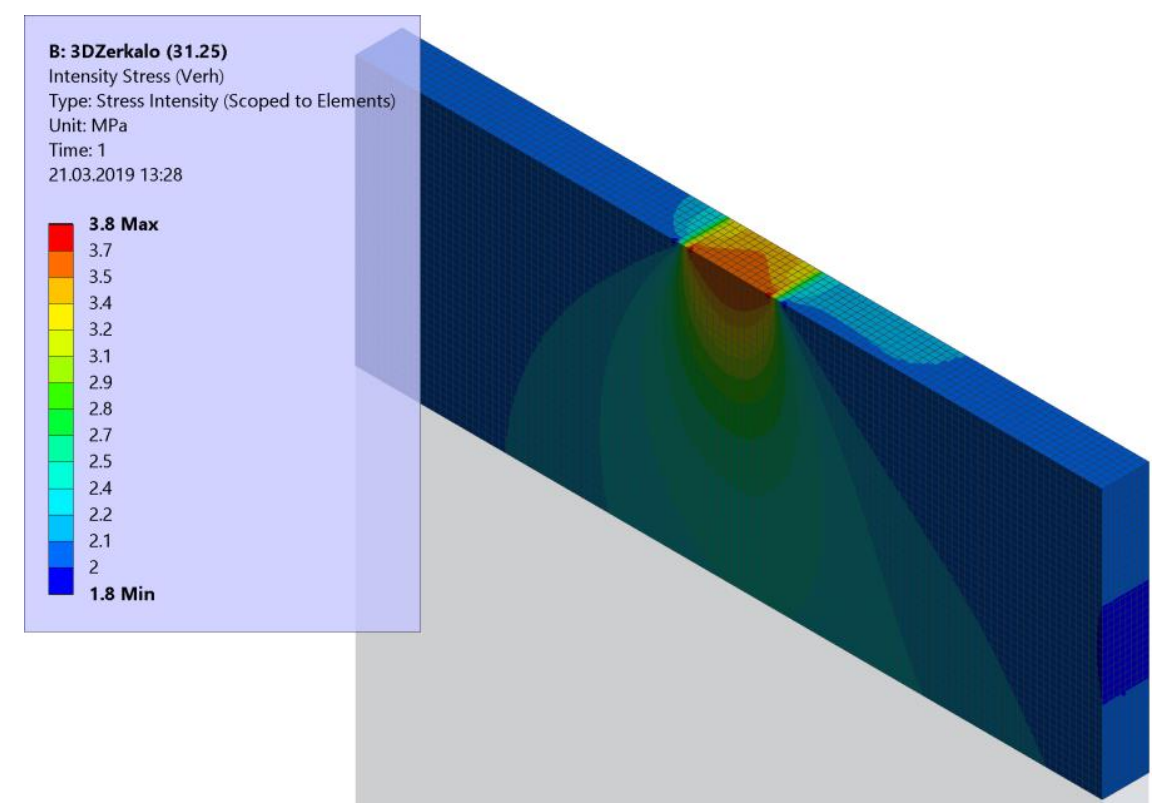

Fig. 6. Distribution of stress intensity $\sigma_{i}$ in the upper part of the deep beam

The value of $\sigma_{i}$ on the top surface of the deep beam in the load application area $q_{f}$. reaches 3.8 $\mathrm{MPa}$. The maximum value of stress intensity in the support region in the lower part of the deep beam equals $57.74 \mathrm{MPa}$.

Based on the calculation results obtained in 3D problem statement one may conclude that a small in length region with the maximum load along the entire thickness of the deep 
beam is located in proximity to the support surface, this region concentrates the maximum stress values in the structural material, as well as maximum linear and angular deformations. The mentioned area of the deep beam is approximately located at the distance of $x$ coordinate between $3.035 \mathrm{~m}$ and $3.125 \mathrm{~m}$ from $z$ axis.

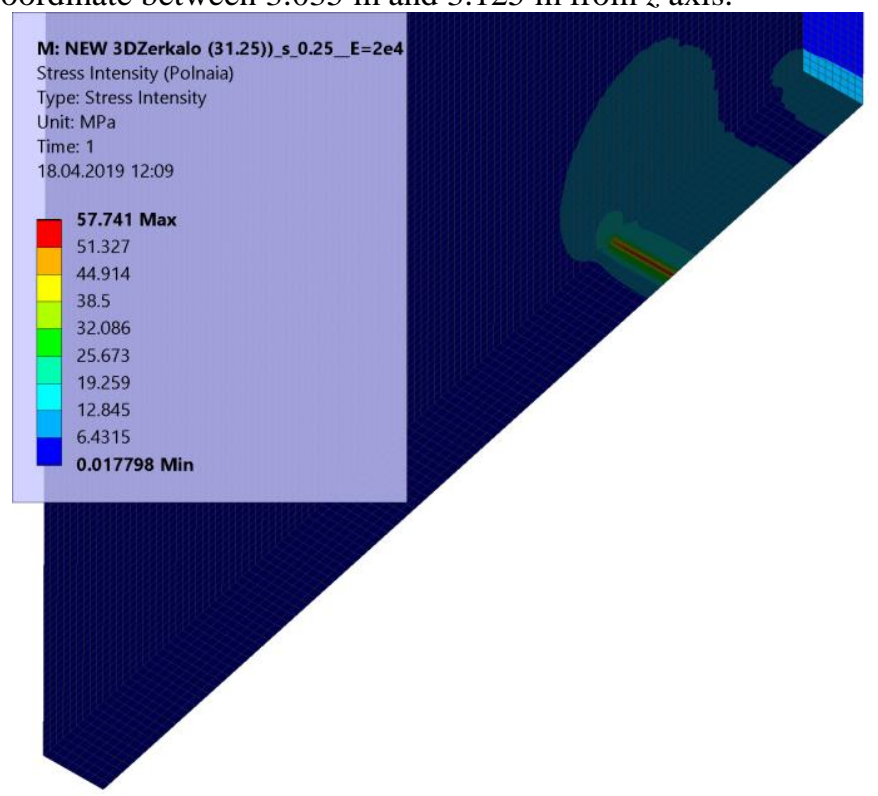

Fig. 7. Distribution of stress intensity $\sigma_{i}$ in the lower part of the deep beam

\subsection{Results for 2D statement}

Calculation of SSS of a deep beam in 2D statement was performed with a finite element mesh with 2D finite elements sized $3.125 \times 3.125 \mathrm{~cm}$. Figures $8-11$ illustrate the calculation results for the following parameters of stress-strain state of the deep beam under study: stresses $\sigma_{y}$ and stress intensity $\sigma_{i}$ in the upper part of the structure where load is applied, and in the lower support part of the structure.

Comparison of the obtained calculation results for determining SSS of the deep beam in 2D and 3D statements provides the following conclusions.

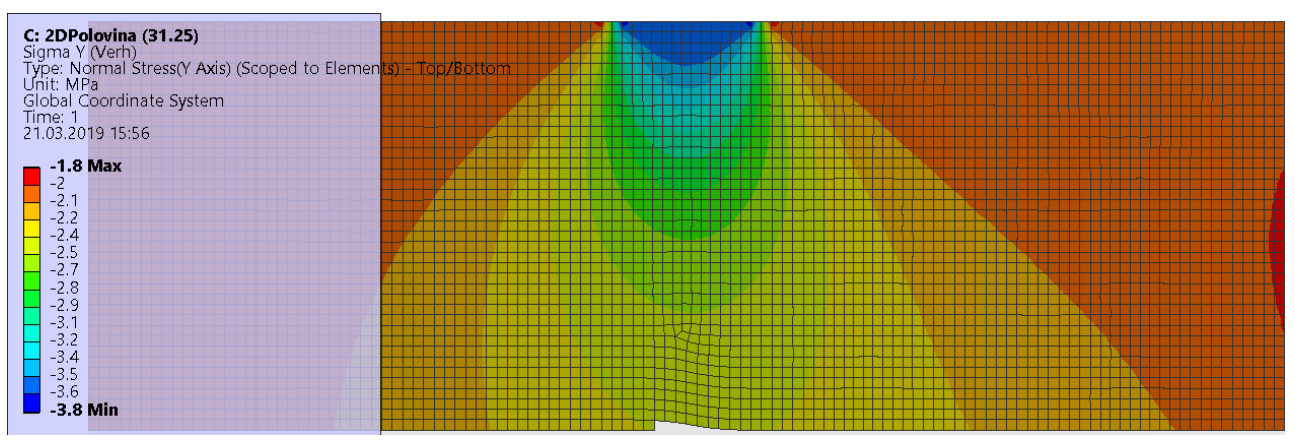

Fig. 8. Distribution of stresses $\sigma_{y}$ in the upper part of the deep beam 


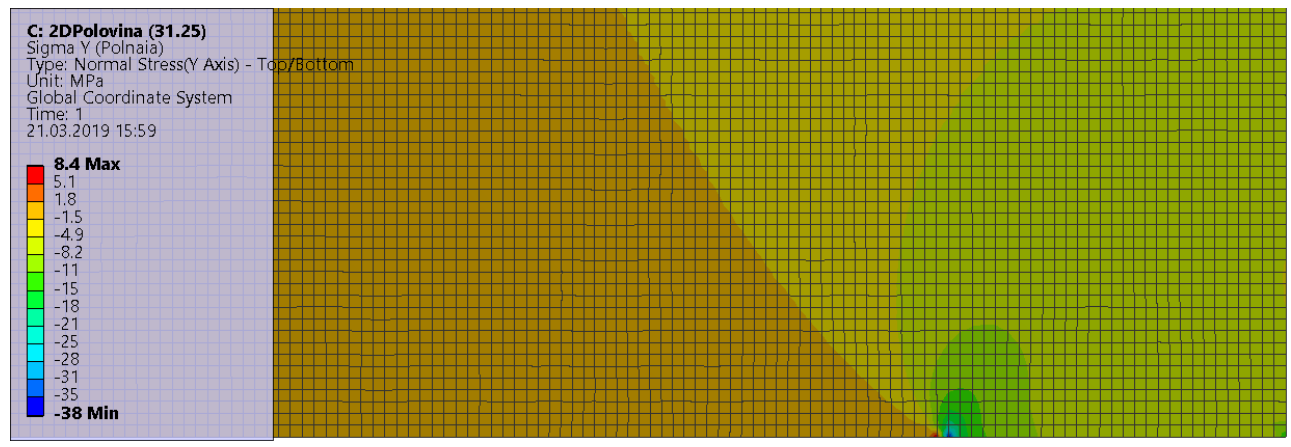

Fig. 9. Distribution of stresses $\sigma_{y}$ in the lower part of the deep beam

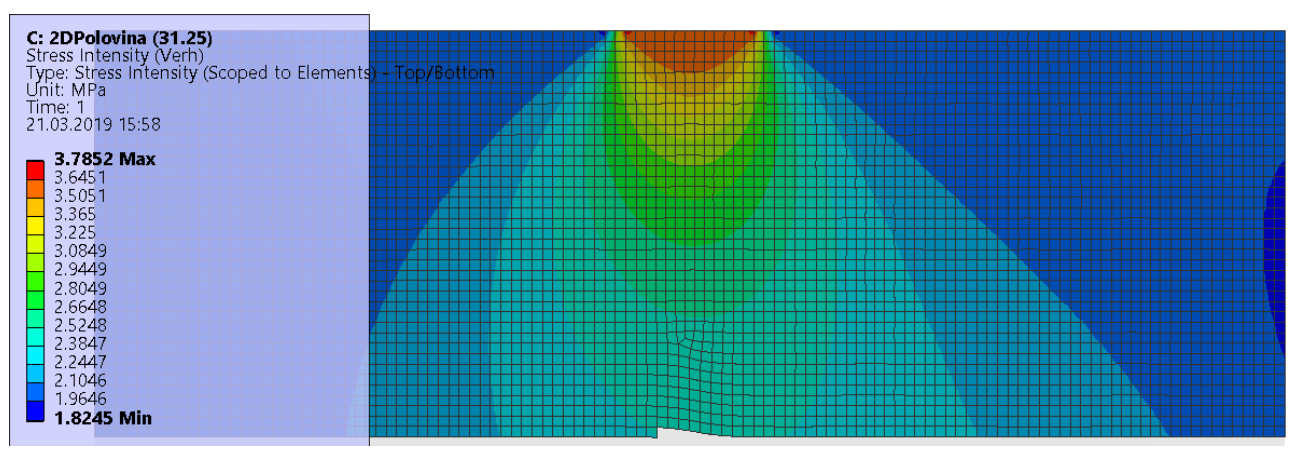

Fig. 10. Distribution of stress intensity $\sigma_{i}$ in the upper part of the deep beam

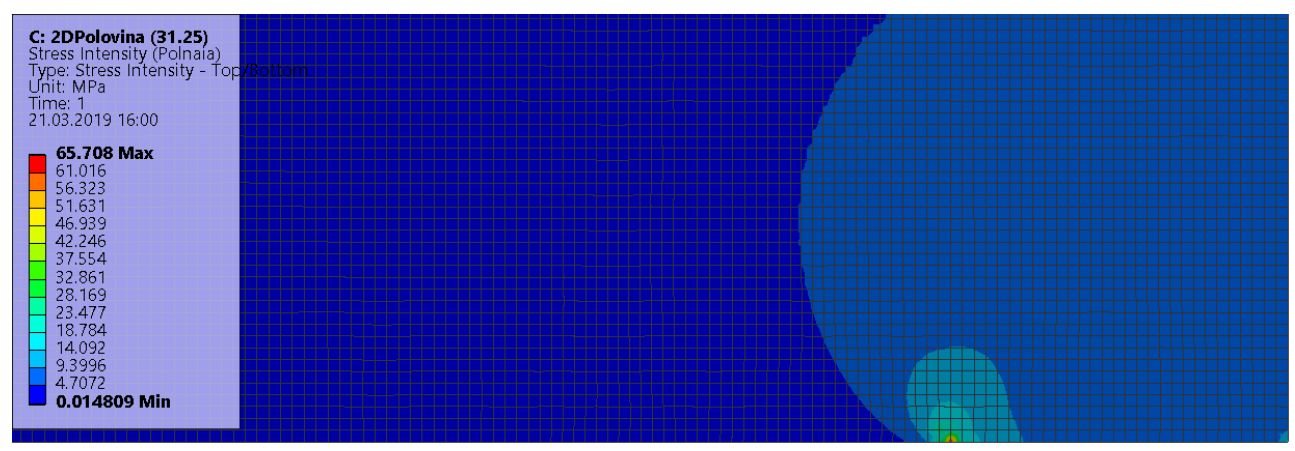

Fig. 11. Distribution of stress intensity $\sigma_{i}$ in the lower part of the deep beam

In the load application area the difference between the values of stresses $\sigma_{y}$ and stress intensity $\sigma_{i}$ for 3D and 2D statements are $0.8 \%$ and $0.4 \%$, respectively. In the support region, where the area with the highest stresses and deformation values is located, the difference between $\sigma_{y}$ and $\sigma_{i}$ for 3D and 2D problem statements increases up to $2.1 \%$ and $13.8 \%$, respectively.

When calculating SSS of structures the parameter of strength intensity is required for strain state analysis with regard to occurrence of elasto-plastic deformations in the material. Due to significant difference of the $\sigma_{i}$ values in the support region obtained for 3D and 2D statements, 3D problem statement shall be used for this deep beam calculation. Besides, solving the problem in this statement is illustrative of distribution of SSS parameters along the thickness of the structure, which is essential for its strength evaluation. 


\subsection{Impact of the values of deep beam thickness and support area on stress- strain state}

Figure 12 presents distribution of stress intensity in the deep beam support region for various thickness values $H=0.50 \mathrm{~m}, H=0.75 \mathrm{~m}$ and $H=1.00 \mathrm{~m}$.

a)

b)

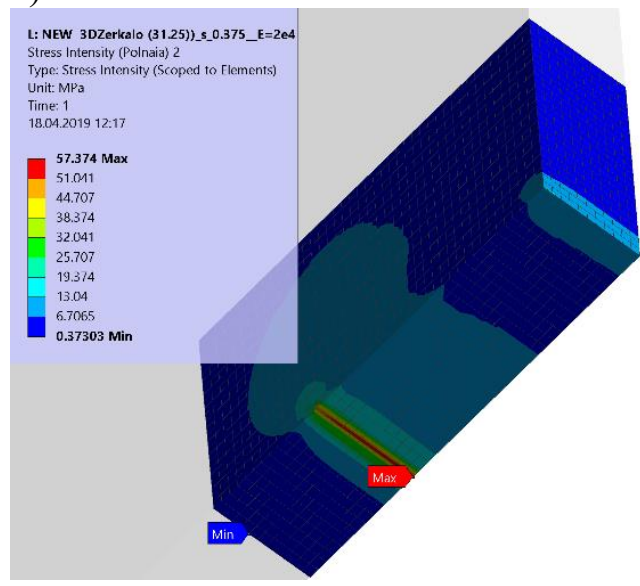

c)

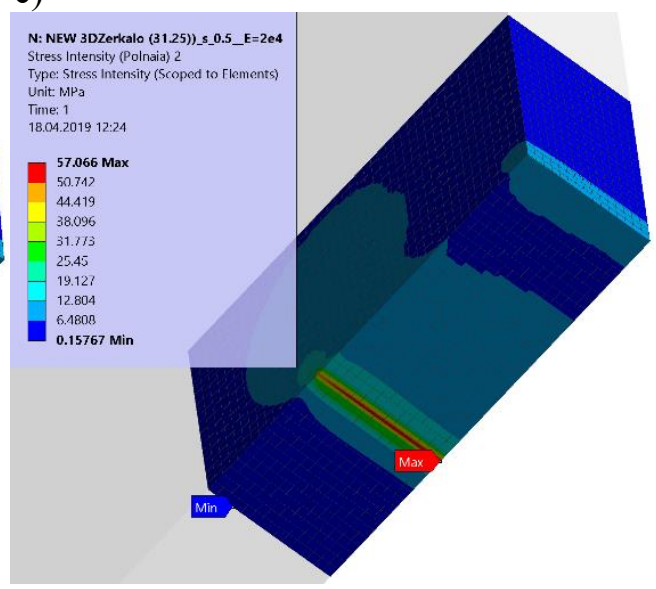

Fig. 12. Distribution of stress intensity $\sigma_{i}$ on the bottom surface of the deep beam $y=0(0 A D H)$ for the following thickness values: a) $H=0.50 \mathrm{~m}$; b) $H=0.75 \mathrm{~m}$; c) $H=1.00 \mathrm{~m}$

When calculating the problem variants with the thickness values of $0.75 \mathrm{~m}$ and $1.00 \mathrm{~m}$ the number of 3D finite elements along the structure thickness increased, however their size parameters remained unchanged and corresponded to those accepted for the basic structure design. Figure 13 demonstrates stress intensity in the lower part of the deep beam for 2D statement.

The given results indicate that with the growth of the deep beam thickness the stress intensity error for 2D and 3D statements shows increase, as expected: from $13.8 \%$ for the basic design variant up to $15.14 \%$ for the thickness of $1.00 \mathrm{~m}$.

For defining the extent of impact of the deep beam support surface on SSS calculations of the basic deep beam design were performed for lower values of support surface.

Distribution of stress intensity $\sigma_{i}$ on the bottom surface of the structure is given in Figure 14. 


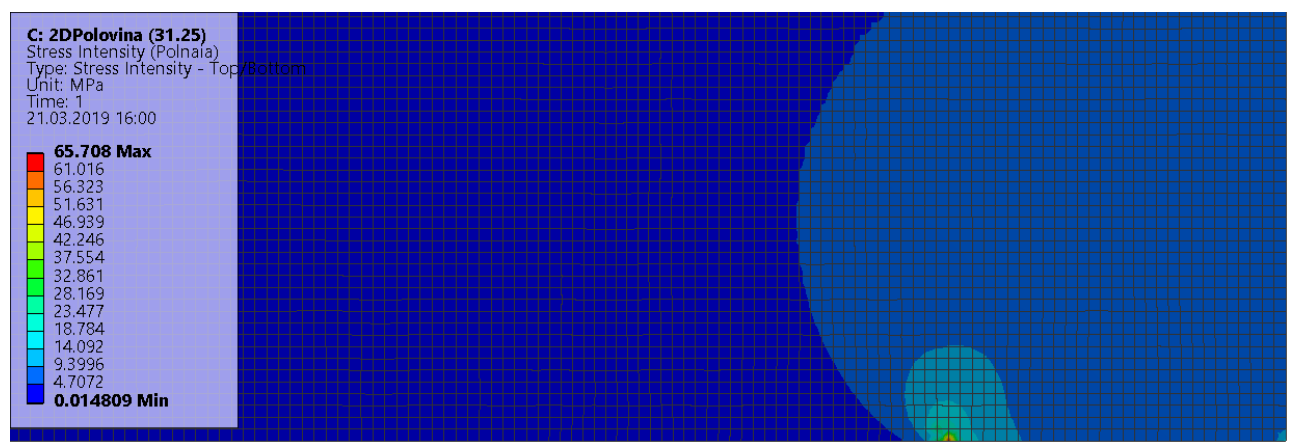

Fig. 13. Distribution of stress intensity $\sigma_{i}$ on the bottom surface of the deep beam $y=0(0 A D H)$ in $2 \mathrm{D}$ statement

a)

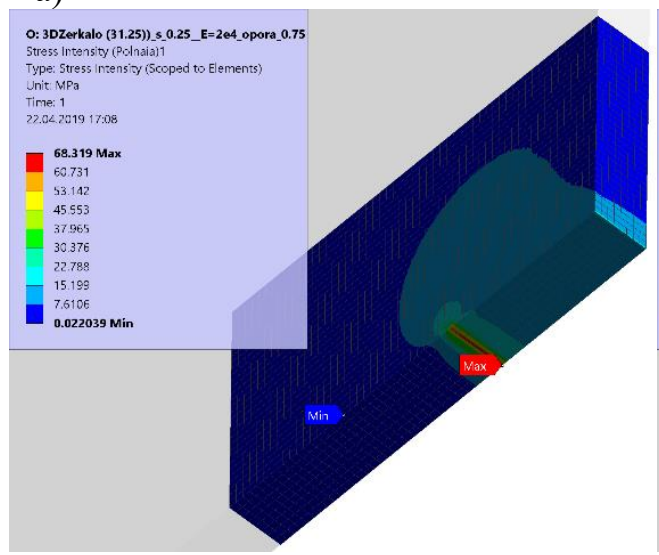

b)

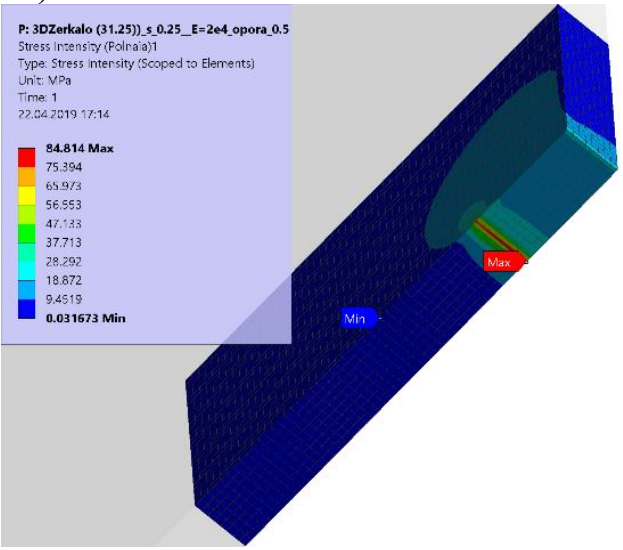

Fig. 14. Distribution of stress intensity $\sigma_{i}$ on the bottom surface of the deep beam for the following values: a) $x_{3}=3.25 \mathrm{~m}$; б) $x_{3}=3.50 \mathrm{~m}$

Compared to the basic deep beam design $\left(x_{3}=3.00 \mathrm{~m}, \sigma_{i}=57.741 \mathrm{MPa}\right)$ reduction of surface area results in a non-linear increase of stress intensity value: for $x_{3}=3.25 \mathrm{~m}$, $\sigma_{i}=68.319 \mathrm{MPa}$; for $x_{3}=3.50 \mathrm{~m}, \sigma_{i}=84.414 \mathrm{MPa}$. Moreover, it shall be noted that the region of maximum stresses and strains has relocated closer to the inner edge of the support.

\section{Conclusion}

1. Based on the performed calculations it was found that the results of a deep beam SSS analysis obtained for 3D statement indicate existence of a short region with the maximum load along the entire thickness of the structure in proximity to the support surface. This region concentrates the maximum values of stresses, as well as maximum linear and angular deformations. The region is located on the symmetry axis of the deep beam $z=0$ near the inner edge of the support surface $x=x_{3}$.

2. It is found that the maximum stress value $\sigma_{z}$ obtained for $3 \mathrm{D}$ problem statement is approximately $50 \%$ different from the stress values $\sigma_{x}$ and $\sigma_{y}$, contrary to the assumption for $2 \mathrm{D}$ statement that it equals to zero. Hence, neglecting the stresses $\sigma_{z}, \tau_{z x}, \tau_{z y}$ will lead to a significant error when determining SSS parameters, particularly stress intensity $\sigma_{i}$.

3 . It is found that the stress intensity values obtained for $3 D$ and $2 D$ statement of the problem on stress-strain state of the deep beam under study considerably differ in this 
region, for that reason $3 \mathrm{D}$ problem statement shall be applied when performing calculations of the deep beam.

4. Solution of the problem in 3D statement is illustrative of distribution of SSS parameters along the thickness of the structure, which is essential for its strength evaluation.

5. The increase of the deep beam thickness $H$ leads to the increase of difference between the stress intensity values $\sigma_{i}$ for $3 \mathrm{D}$ and $2 \mathrm{D}$ statements. For $3 \mathrm{D}$ problem statement reduction of surface area results in a non-linear increase of stress intensity value.

\section{References}

1. A.P. Sinitsyn, Vestnik Voenno-inzhenernoj akademii RKKA. Sbornik po stroitel'noj mehanike [Journal of Russian Military and Engineering Academy. Structural Mechanics] 3 (1), 15-30, (1934) (in Russian)

2. I.I. Goldenblat, Raschet $i$ konstruirovanie zhelezobetonnyh balok-stenok [Calculation and construction of reinforced concrete deep beams], 84, (1940) (in Russian)

3. A.S. Kalmanok, Raschet balok-stenok [Calculation of deep beam], 145, (1957) (in Russian)

4. B.N. Zhemochkin, Teorija uprugosti [Theory of elasticity], 257, (1957) (in Russian)

5. V.A. Kiselev, Ploskaja zadacha teorii uprugosti [Plane problem in theory of elasticity], 151, (1976) (in Russian)

6. V.I. Samul, Osnovy teorii uprugosti $i$ plastichnosti [Basics of the theory of elasticity and plasticity], 264, (1982) (in Russian)

7. A.V. Aleksandrov, V.D. Potapov, Soprotivlenie materialov. Osnovy teorii uprugosti $i$ plastichnosti [Strength of materials. Basics of the theory of elasticity and plasticity], 400, (2002) (in Russian)

8. G.S. Vardanyan, V.I. Andreev, N.M. Atarov, A.A. Gorshkov, Soprotivlenie materialov $s$ osnovami teorii uprugosti i plastichnosti [Strength of materials with the basics of the theory of elasticity and plasticity], 638, (2011) (in Russian)

9. V.N. Barashkov, I.Y. Smolina, L.E. Puteeva, D.N. Pestsov, Osnovy teorii uprugosti [Basics of the theory of elasticity], 184, (2012) (in Russian)

10. V.N. Barashkov, A.A. Matveenko, Vestnik of TSUAB, 3, 92-104, (2010) (in Russian) 